\title{
ESTUDO DO SOLO-CIMENTO-AUTOADENSÁVEL PRODUZIDO COM SOLOS DA REGIÃO DO PORTO-PT. PARTE I: CARACTERIZAÇÃO DE PROPRIEDADES MECÂNICAS
}

\section{Study of the self-compacting soil-cement produced with soils from the Porto-Pt. Part I: Characterization of a mechanical properties}

\author{
Marco Antônio de Morais Alcantara ${ }^{1}$ Sandra Conceição Barbosa Nunes ${ }^{2}$, \\ João Filipe Meneses Espinheira Rio ${ }^{3}$
}

Recebido em 16 de maio de 2014; recebido para revisão em 11 de julho de 2014; aceito em 26 de agosto de 2014; disponivel on-line em 06 de setembro de 2014.

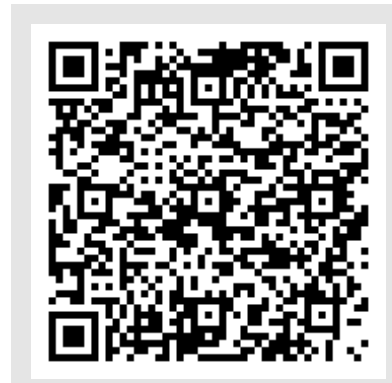

PALAVRAS CHAVE:

Solo-cimento;

Autoadensável;

Reologia;

Compacidade;

\section{KEYWORDS:}

Soil-cement;

Self-compacting,

Rheology;

Compactness.

\footnotetext{
* Contato com os autores:
} Ver página seguinte

\begin{abstract}
RESUMO: O artigo apresenta um estudo do solo-cimento autoadensável, fluido, buscando associar alguns parâmetros de dosagem com o desempenho mecânico resultante, e procurando tomar em consideração as condições de compacidade alcançadas no processo. Busca ainda apresentar uma visão geral do comportamento reológico no estado fresco. Para tanto, foi realizado um experimento a partir da utilização de um solo residual da região do Porto-Pt, cimento Portland, água, e aditivo de atuação estérica e eletrostática. A proporção dos materiais foi adotada a partir do peso seco do solo, conforme teores que variaram de 20,25 , e $30 \%$ de cimento, 41,44 e $47 \%$ para a água, e $0,66,0,80$ e $0,93 \%$ para a variação do teor do superplastificante. Os ensaios realizados no estado fresco procuraram seguir os protocolos de avaliação utilizados para os casos de argamassas, e de concretos autoadensáveis; dentre eles, os ensaios de espalhamento com a utilização do mini-cone, de fluidez com o auxílio do funil; e, no estado endurecido, foram realizados os ensaios de resistência à compressão simples, resistência à flexão, de avaliação da massa específica aparente, e de porosimetria. Os resultados do estado fresco indicaram haver aproximação entre o solo-cimento-auto-adensável e os concretos e argamassas; os valores de resistência mecânica apresentaram correlação com os valores da relação água/cimento, variando entre 2,7 e 6,5 MPa para os casos de resistência à compressão simples; bem como, os valores de resistência à flexão se apresentaram proporcionais aos valores de resistência à compressão simples. As variações no valor da resistência mecânica guardaram relações preferencialmente com os valores das relações água/cimento, do que com os valores alcançados para as massas específicas aparentes alcançadas, e da porosimetria.
\end{abstract}

ABSTRACT: The article presents a study of the soil-cement self-compacting, fluid, seeking associate some dosing parameters with the resulting mechanical performance, and trying to take into account the condition of compactness achieved in the process. It also seeks to provide an overview of the rheological behavior in the fresh state. Therefore, an experiment was conducted from the use of a residual soil of the region of Porto-Pt, Portland cement, water and additive steric and electrostatic actuation. The proportion of the materials was adopted as the dry weight of soil as contents ranging from 20, 25, and $30 \%$ cement, 41 , and 44 to $47 \%$ water, and $0.66,0.84$ and $093 \%$ for the variation of the content of the superplasticizer. The tests carried out in the fresh state sought to follow the evaluation protocols used for cases of mortars, concretes and self-compacting, among them, the scattering assays using the mini cone, with the aid of fluidity of the funnel; and, in the hardened state, the tests were performed compressive strength, flexural strength, evaluation of the apparent density and porosimetry. The results of the fresh state showed good approximation of the soil-cement-and self-compacting concrete and mortar, the mechanical resistance values were correlated with the values of the water / cement ratio, ranging between 2.7 and $6.5 \mathrm{MPa}$ for cases of compressive strength, as well as the values of flexural performed proportional to the values of compressive strength. Changes in the value of the mechanical strength relations preferably with the values of the water / cement ratio, than the values obtained for the apparent densities achieved, relationships and porosimetry. 


\footnotetext{
* Contato com os autores:

${ }^{1}$ e-mail :alcantar@dec.feis.unesp.br ( M. A. de M. Alcantara )

Professor Assistente, Doutor, Departamento de Engenharia Civil - Faculdade de Engenharia de IIha Solteira (FEIS/UNESP).

2e-mail : snunes@fe.up.pt (S.C.B. Nunes )

Professora Auxiliar, Doutora, Departamento de Engenharia Civil - Faculdade de Engenharia da Universidade do Porto (FEUP),

${ }^{3}$ e-mail : joao.rio@fe.up.pt (J. F. M. E. Rio )

Investigador Auxiliar, Doutor, Departamento de Engenharia Civil - Faculdade de Engenharia da Universidade do Porto (FEUP).
}

\section{INTRODUÇÃO}

A estabilização de solos é uma prática bastante antiga, estando ela presente ao longo de diversas civilizações para a solução dos problemas de construção de infraestrutura. $\mathrm{Na}$ atualidade esta técnica ressurgiu a partir da junção da mecânica de solos e das áreas de ciências do solo, criando um repertório técnico capaz de explorar recursos materiais, e de intervir de maneiras diversas como: (1) com a exploração de ações mecânicas e térmicas, (2) com a incorporação de aditivos químicos de modo a se produzir material cimentante, ou ainda, (3) com a presença de inclusões ao solo, criando o efeito de estrutura.

O solo-cimento é um material de construção resultante do processo químico de estabilização de solos com cimento. De modo geral se utilizam preferencialmente solos de natureza arenosos ou areno-siltosos, onde, o cimento hidratado forma uma matriz que envolve as partículas de solo, ficando estas com o papel de microagregados. Este material tem sido utilizado ao longo dos tempos para a solução de problemas em engenharia, tendo objetivos diversos, procurando-se atender a requisitos de desempenho, específicos.

Tradicionalmente o solo-cimento tem sido aplicado sob condições de moldagem e conformação envolvendo meios mecânicos de compactação, implicando-se em massas específicas compatíveis com o processo, e com posterior qualificação após o ganho de resistência na cura. Neste caso, podem ser incluídos os solo-cimento empregados nas obras de pavimentação, construção de aterros, e barragens, a partir de serviços de compactação no campo, e também a produção de materiais de construção, como nos casos dos tijolos e blocos prensados.
A utilização do solo-cimento traz como vantagem a possibilidade de se aproveitar o material local, e de permitir autonomia dentro do canteiro, onde o material solo é bastante disponível, favorecendo a aplicação tanto no meio urbano como no meio rural. Este material tem sido produzido para obras de habitação tanto na forma prensada como na forma fluida preenchendo fôrmas, explorando-se a sua deformabilidade no estado plástico. Considerando que o uso deste material tem sido adequado para diversos tipos de aplicações, acredita-se que é importante uma discussão pertinente quanto à qualificação deste material sob os pontos de vista tecnológicos, com as possibilidades de se inovar este tipo de solução.

\section{OBJETIVOS}

O objetivo deste trabalho foi de avaliar o comportamento de misturas solo-cimento com comportamento autoadensável, variando alguns parâmetros de dosagem, visando encontrar correspondências entre estes parâmetros e o comportamento mecânico, assim como com as condições de compacidade alcançadas no processo. Buscou-se ainda avaliar o comportamento reológico das misturas no estado fresco, adotando-se protocolos de ensaios que são aplicados aos casos dos concretos e de argamassas.

\section{REVISÃO BIBLIOGRÁFICA}

O solo-cimento na forma autoadensável deve ser capaz de atender ao requisito de poder se adensar unicamente sob a ação do seu peso próprio, de maneira análoga aos casos de concretos autoadensáveis, os quais, conforme Alcantara (2004), devem ser fluidos, sem que apresentem os fenômenos da exsudação e da 
segregação, e preencham facilmente os moldes sem a presença de bloqueios. Considera-se importante estabelecer uma diferenciação entre o solo-cimento tradicional, compactado, e o solo-cimento na forma autoadensável, sobretudo em termos dos parâmetros de dosagem e dos aspectos tecnológicos. Tem-se que, quanto aos casos do solo-cimento compactado, embora a quantidade de água incorporada ao solo tenha importância para o processo tecnológico, assim como a quantidade de cimento, algumas dificuldades têm sido encontradas em se adotar o fator a/c como variável de estudo e parâmetro de dosagem (CONSOLI et al., 2007 e FONSECA et al., 2009).

De acordo com Fonseca et al. (2009), a isto podem ser atribuídas questões particulares relativas à compactação dos solos, como a estrutura do solo, a energia aplicada, e a ação físico-química decorrente da presença da água e dos constituintes do solo. Os autores consideram de modo unânime que para o caso do solo-cimento compactado a relação que melhor poderia apresentar correlação com o valor da resistência à compressão simples é a combinação entre a quantidade de vazios do solo com o volume de cimento adicionado, a qual pode expressar a influência na porosidade final das misturas. Por outro lado, resultados diferentes podem ser apresentados em Horpbilsuk (2003), onde o parâmetro água-cimento se apresentou como parâmetro de referência para o valor da resistência mecânica em um caso estudado de misturas de solo-cimento. Conforme Fonseca et al. (2009), a quantidade de água incorporada nestas misturas era alta o suficiente para que esta tivesse relação com a quantidade de vazios do solo, isto é, segundo os autores, similar ao que acontece com o caso do concreto de cimento Portland, onde, a quantidade de água reflete a quantidade vazios presente na fase de argamassa.

Segantini e Alcantara (2010) apresentam o solo-cimento plástico, concebido de modo a ser compactado sob a ação do seu peso próprio, utilizado particularmente para a produção de estacas moldadas "in loco", cujos requisitos de desempenho estão relacionados às exigências geotécnicas para fundações. De acordo com Segantini e Alcantara (2010), para a dosagem do solo-cimento plástico a utilização dos teores de cimento deve ser, em peso, $4 \%$ acima daqueles sugeridos para o solo-cimento compactado, quando na sua massa específica máxima. Alertam os autores que "alguns tipos de solo, sobretudo os mais finos, requerem quantidades elevadas de água para se conseguir a consistência plástica desejada, similar a uma argamassa de emboço. Nesses casos, deve-se levar em consideração a relação água/cimento na sua dosagem, sendo ideal uma relação "a/c $<1,0$ ". Neste sentido misturas solo-cimento passam a serem compreendidas como mistura íntima entre os constituintes: solo, cimento, e água, sendo as misturas alcançadas por meio de misturadores mecânicos utilizados na construção civil.

Com base nas possíveis propriedades de auto adensabilidade das misturas de solo-cimento, fluidificadas por meio do auxílio de aditivos superplastificantes, Berté e Alcantara (2013) apresentam um estudo visando a auto adensabilidade do solo-cimento, de maneira que este possa ser aplicado para a fabricação de elementos diversos quanto à forma, atendendo a diferentes classes de resistência mecânica, e devendo atender também às exigências que favoreçam a durabilidade. Este tem como vantagem dispensar o uso de equipamentos de prensagem, e requerem a utilização de equipamentos básicos para a realização da mistura, visando atender à produção de componentes para a construção civil.

\section{MATERIAL E MÉTODOS}

Para o desenvolvimento desta pesquisa foram utilizados os seguintes materiais: solo residual saprolítico da região de Porto - Pt, cimento Portland do tipo cimento CEM I 42.5, superplastificante de ação estérica e eletrostática, e água.

Dentro do seu plano de ensaio a metodologia buscou que se explorasse a influência dos agentes fluidificantes, dados pela água e pelo superplasticante, a dos agentes de viscosidade, dados pelo cimento e o solo. As misturas para esse 
estudo são apresentadas no Quadro 1.

Conforme o Quadro 1, as misturas podem se distinguir da seguinte forma: (1) as misturas 1, 2, 3, 4, e 5, apresentam condições iguais quanto à relação superplasticante/solo, diferenciado-se quanto às relações cimento/solo e água/solo; (2) as misturas 1, 2 e 3 apresentam a mesma relação cimento/solo, variando quanto à relação água/cimento; (3) as misturas 1, 4, e 5 apresentam a mesma relação água/solo, diferenciando-se quanto à relação cimento/solo. Já as misturas 6 e 7 apresentam relação superplastificante/solo variável, e igualdade nas relações água/solo e cimento/solo e são apresentadas no Quadro 2.

QUADRO 1: Mistura adotadas no estudo experimental, dadas em peso, para os casos em que se mantém constante as relações superplastificante/ solo.

\begin{tabular}{|c|c|c|c|c|c|c|}
\hline \multicolumn{7}{|c|}{ Caso do superplastificante/solo mantido fixo } \\
\hline & & $\begin{array}{l}\text { Mistura } 1 \\
\text { Referência }\end{array}$ & Mistura 2 & Mistura 3 & Mistura 4 & Mistura 5 \\
\hline \multicolumn{2}{|l|}{ Solo (g) } & 1508,33 & 1508,33 & 1508,33 & 1508,33 & 1508,33 \\
\hline \multicolumn{2}{|l|}{$\begin{array}{l}\text { Cimento CEM I } 42.5 \\
\text { R-Secil-Maceira (g) }\end{array}$} & 301,67 & 301,67 & 301,67 & 377,08 & 452,50 \\
\hline \multicolumn{2}{|l|}{ Água } & 663,67 & 708,92 & 618,42 & 663,67 & 663,67 \\
\hline \multicolumn{2}{|c|}{ Supeplastificante (V3008) (g) } & 12,07 & 12,07 & 12,07 & 12,07 & 12,07 \\
\hline \multicolumn{2}{|l|}{ Água 1 (g) } & 530,93 & 567,13 & 494,73 & 530,93 & 530,93 \\
\hline \multicolumn{2}{|l|}{ Água 2 (g) } & 132,73 & 141,78 & 123,68 & 132,73 & 132,73 \\
\hline \multirow{3}{*}{$\begin{array}{l}\text { Relações entre os } \\
\text { constituintes das } \\
\text { misturas }\end{array}$} & cimento/solo & \multicolumn{3}{|c|}{$20 \%$} & $25 \%$ & $30 \%$ \\
\hline & agua/solo & $44 \%$ & $47 \%$ & $41 \%$ & --- & --- \\
\hline & sup/solo & $0,80 \%$ & $0,80 \%$ & $0,84 \%$ & $0,80 \%$ & $0,80 \%$ \\
\hline
\end{tabular}

QUADRO 2: Mistura adotadas no estudo experimental, dadas em peso para os casos em que se variam as relações superplastificante/ solo.

\begin{tabular}{|c|c|c|c|c|c|}
\hline \multicolumn{6}{|c|}{ Caso do superplastificante/solo variável } \\
\hline & & $\begin{array}{l}\text { Mistura 1- } \\
\text { referência }\end{array}$ & Mistura 6 & Mistura 7 & \\
\hline \multicolumn{2}{|l|}{ Solo (g) } & 1508,33 & 1508,33 & 1508,33 & \\
\hline \multicolumn{2}{|l|}{$\begin{array}{l}\text { Cimento CEM I } 42.5 \\
\text { R-Secil-Maceira (g) }\end{array}$} & 301,67 & 301,67 & 301,67 & \\
\hline \multicolumn{2}{|l|}{ Água } & 663,67 & 663,67 & 663,67 & \\
\hline \multicolumn{2}{|c|}{ Supeplastificante (V3008) (g) } & 12,07 & 10 & 14 & \\
\hline \multicolumn{2}{|l|}{ Água 1 (g) } & 530,93 & 567,13 & 494,73 & \\
\hline \multicolumn{2}{|l|}{ Água 2 (g) } & 132,73 & 141,78 & 123,68 & \\
\hline \multirow{3}{*}{$\begin{array}{c}\text { Relações entre os } \\
\text { constituintes das } \\
\text { misturas }\end{array}$} & cimento/solo & \multicolumn{3}{|c|}{$20 \%$} & \\
\hline & agua/solo & \multicolumn{3}{|c|}{$44 \%$} & \\
\hline & sup/solo & $0,80 \%$ & $0,66 \%$ & $0,93 \%$ & \\
\hline
\end{tabular}


Quanto aos procedimentos da amassadura, de início eram dispostos em uma cuba metálica do misturador o solo, o cimento, e a água, conforme a designação de "água 1". Eram então misturados em velocidade lenta pelo período de 60 segundos, quando, então, era interrompida a mistura para que se efetuasse a raspagem do material aderido à pá do misturador. Em seguida, a mistura era retomada por um período de mais 60 segundos, sendo, então, novamente interrompida para a incorporação da água restante, "água 2", juntamente com o superplastificante. Assim, a mistura era imediatamente retomada pelo período adicional de 60 segundos, também em velocidade lenta, sendo novamente interrompida para outra raspagem do material aderido à pá do misturador. Em continuidade, a mistura era retomada por um período de mais 30 segundos em velocidade lenta, seguida de uma interrupção e pausa de 60 segundos, de maneira que o superplastificante pudesse ter maior efeito e, finalmente, a mistura era retomada por um período final de 30 segundos, em velocidade rápida, estando então concluída a mistura. A Figura 1 ilustra a sequência deste procedimento.

Uma vez concluídas as misturas, se procedia a realização dos ensaios de validação no estado fresco: os ensaios de espalhamento em escoamento livre, "slump-flow", e em escoamento confinado, por meio do ensaio do funil. Feitos os ensaios do estado fresco, procedia-se a moldagem, vertendo-se o conteúdo da cuba do misturador nos moldes específicos, sem o auxílio de vibração ou de qualquer outro esforço mecânico, contando exclusivamente com a energia dada pelo peso próprio do material. Como moldes foram utilizadas formas permitindo a fabricação de 3 corpos de prova prismáticos de $4 \times 4 \times 6 \mathrm{~cm}$, e moldes cilíndricos com diâmetro de $46 \mathrm{~mm}$ e altura de 31 $\mathrm{mm}$.

Os corpos de prova prismáticos eram então encaminhados para a câmara úmida, para a cura, sendo estes avaliados pelo período de cura de 7, 14 e 28 dias quanto à resistividade, e sujeitos aos ensaios de flexão simples e compressão simples aos 28 dias de cura. Foram realizados os ensaios de espalhamento "slump-flow", o qual procura avaliar o material em escoamento livre, e o ensaio $V$ funil, o qual procura avaliar o desempenho do material em escoamento sob confinamento. 0 procedimento adotado para o ensaio de espalhamento é bastante simples, e pode ser compreendido conforme descrito em NUNES (2001), as dimensões do cone eram dadas conforme a Figura 2. O procedimento é dado pelos seguintes: era umedecida inicialmente o interior do cone e a superfície de uma placa metálica, com um pano úmido; se colocava a placa sobre uma superfície firme, plana e nivelada; após o final da amassadura, se enchia o cone com uma amostra ou pasta ou argamassa, nivelava o topo do cone e, em seguida, levantava-o de forma cuidadosa e contínua o cone vertical; no final do movimento, media-se o diâmetro aparentemente máximo da área de espalhamento e o diâmetro perpendicular a este. A Figura 2 ilustra um caso de avaliação da superfície de espalhamento.

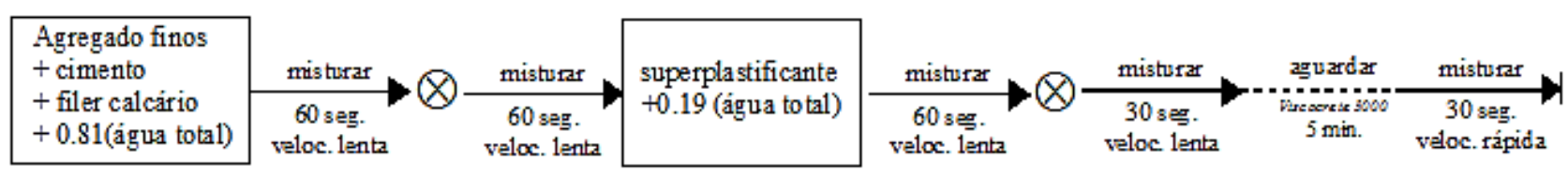

$Q$ retirar material aderente nas paredes e pás da misturadora

FIGURA 1: Procedimento normalizado utilizado para a fase de mistura. 


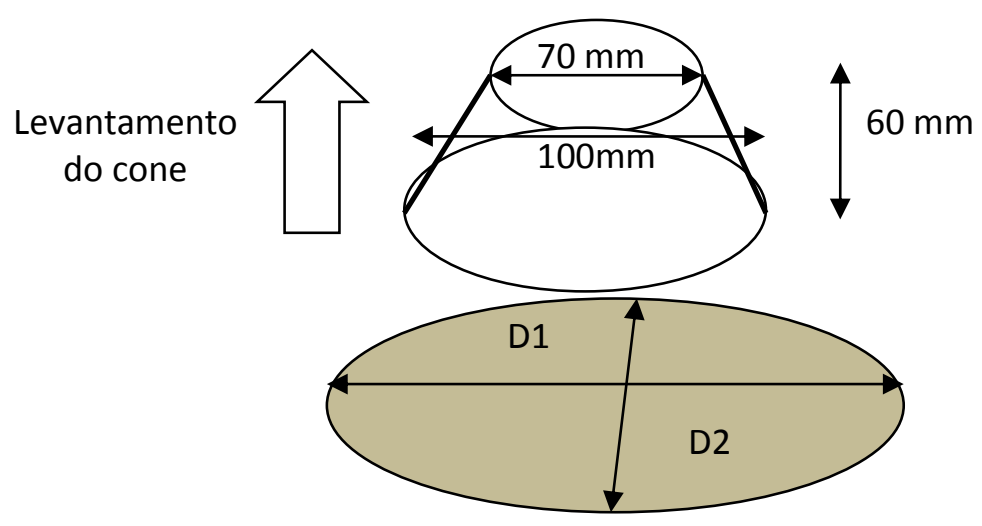

FIGURA 2: Medição dos diâmetros de espalhamento.

Quanto ao ensaio do $V$ funil, o procedimento do ensaio se deu conforme os relatos de Nunes (2001) e Alcantara (2004), em um funil com as dimensões apresentadas na Figura 3:

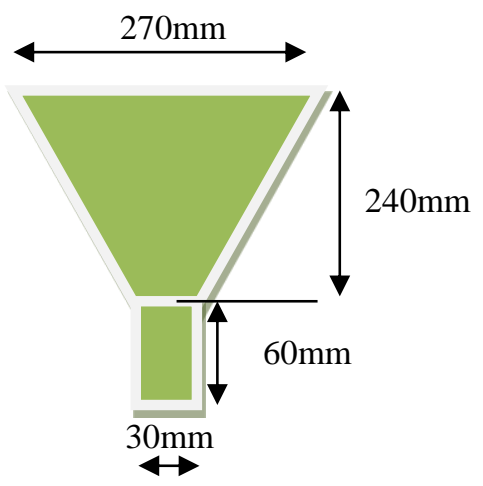

FIGURA 3: Avaliação do tempo em escoamento confinado com o auxílio do V-funil.

Os procedimentos adotados no ensaio $\mathrm{V}$ funil foram os seguintes: umedecia-se o interior do funil com um pano úmido; colocava-se o funil na estrutura de suporte que estava sobre uma superfície plana, nivelada e firme: posicionava o recipiente para receber a argamassa e fechava a comporta inferior; enchia-se então completamente o funil com a argamassa, de forma contínua e sem qualquer tipo de vibração, e nivelava-se a argamassa na parte superior; em seguida, abria-se a comporta, iniciando simultaneamente a contagem do tempo utilizando um cronômetro. Observava-se o movimento pela parte superior e parava-se a contagem do tempo com o aparecimento dos primeiros pontos de luz no fundo do funil.

Os ensaios de flexão foram realizados a partir de cargas centradas em corpos de prova em forma de vigas prismáticas com dimensões de $4 \times 4 \times 16 \mathrm{~cm}$, dotados de uma ranhura na posição central inferior de modo a se orientar a abertura de fissuras. A velocidade de aplicação da carga foi de $0,01 \mathrm{~m} / \mathrm{s}$, e foi efetuado o controle tanto da força como da deformação do corpo de prova. Os ensaios de resistência à compressão simples foram realizados conforme o procedimento descrito na norma NP EN 196-1, apresentado em IPQ (1996), com ligeiras modificações propostas segundo NUNES (2001). A aplicação da carga durante o ensaio foi realizada com o controle do deslocamento, à velocidade de aplicação dada por $0,01 \mathrm{~m} / \mathrm{s}$ até a ruptura. Os corpos de prova eram originários do desmembramento do prisma de $4 \times 4 \times 16 \mathrm{~cm}$ em 4 cubos. As Figuras $4 \mathrm{a}$ e 4b ilustram os ensaios de resistência à flexão e de resistência à compressão simples.

Os procedimentos adotados para os ensaios de avaliação da porosidade e da massa específica foram conforme informações que são apresentadas em Nunes (2001), e constam de: Os corpos de prova, em forma de discos de $46 \mathrm{~mm}$ de diâmetro e $31 \mathrm{~mm}$ de altura são previamente preparados para se garantir a completa condição de saturação. Após o período de cura os corpos de prova são colocados em vácuo, 10-50mbar, durante 4 horas e, com a bomba de vácuo ainda em funcionamento por mais de uma hora são submergidos em água. Segue-se então um período de $18 \mathrm{~h}$ em que os corpos de prova são mantidos debaixo d'água. Após esta preparação é 
determinada a sua massa hidrostática, dada por Mágua, e a sua massa no ar, dada por $\mathrm{M}_{\mathrm{ar}}$. Posteriormente colocam-se os corpos de prova numa estufa a $105 \stackrel{\circ}{\circ}+/-1 \stackrel{\circ}{ }$, até atingirem massa constante, considerando-se o corpo de prova seco, ou seja, quando a diferença entre as pesagens sucessivas $m_{i}$ e $m_{i+1}$, decorridos mais de 24 horas de intervalo entre elas, for inferior a 0,05\% $\mathrm{m}_{\mathrm{i}}$. Para a avaliação da porosidade acessível à água utiliza-se a Equação 1.

$$
\varepsilon(\%)=\frac{M_{a r}-M_{\text {seco }}}{V}=\frac{M_{a r}-M_{\text {seco }}}{M_{\text {ar }}-M_{\text {agua }}} \times \rho_{\text {agua }} \times 100 \text { Eq. [1] }
$$

Onde:

$\mathbf{M}_{\mathrm{ar}}$ é a massa do corpo de prova no $\operatorname{ar}\left(\mathrm{g}_{\mathrm{r}}\right)$;

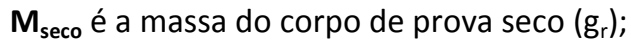

$\mathbf{M}_{\text {água }}$ é a massa hidrostática do corpo de prova $\left(\mathrm{g}_{\mathrm{r}}\right)$;

Págua é a massa volúmica da água à temperatura do ensaio $\left(\mathrm{g}_{\mathrm{r}} / \mathrm{mm}^{3}\right)$.

Com o auxílio de pastilhas utilizadas para os ensaios de porosidade eram vertidas as misturas as quais foram rasadas na superfície. A partir do volume conhecido e do peso do material vertido foi possível avaliar a massa específica aparente das misturas. Se adotou três unidades experimentais para cada caso de mistura tanto para a avaliação da porosimetria como para a avaliação da massa específica.

\section{RESULTADOS e DISCUSSÃO}

O Quadro 3 apresenta os resultados dos ensaios realizados no estado fresco, para os casos de escoamento livre, ensaio de espalhamento, ainda para os casos de escoamento confinado, referentes aos ensaios do funil.

As superfícies de espalhamento apresentaram-se homogêneas, sem a presença de ninhos de concentração, irregularidades na altura ou na distribuição do material e, também, sem apresentar halos d'água que seriam indicativos de segregação. As superfícies de espalhamento eram bastante circulares. As Figuras $5 a$ e $5 b$ ilustram exemplos de superfícies de espalhamento, referentes percebidas nos ensaios.

\begin{tabular}{|c|c|c|c|c|c|c|c|}
\hline & \multicolumn{7}{|c|}{ Resultados dos ensaios no estado fresco em ensaios de espalhamento "slump-flow" } \\
\hline & \multicolumn{7}{|c|}{ Mistura } \\
\hline $\begin{array}{l}\text { Diâmetros de } \\
\text { espalhamento }\end{array}$ & M1-ref. & $\mathrm{M} 2$ & M3 & M4 & M5 & M6 & M7 \\
\hline $\mathrm{D}_{1}(\mathrm{~mm})$ & 278,5 & 332 & 205 & 239 & 215 & 256 & 307 \\
\hline $\mathrm{D}_{2}(\mathrm{~mm})$ & 279 & 334 & 209 & 245 & 219 & 264 & 331 \\
\hline \multirow[t]{3}{*}{$D_{\text {médio }}(\mathrm{mm})$} & 278,5 & 333 & 207 & 242 & 217 & 260 & 319 \\
\hline & \multicolumn{7}{|c|}{$\begin{array}{l}\text { Resultados dos ensaios no estado fresco em ensaios de avaliação do tempo de escoamento em } \\
\text { "V-funil". }\end{array}$} \\
\hline & M1-ref. & $\mathrm{M} 2$ & M3 & M4 & M5 & M6 & M7 \\
\hline $\begin{array}{c}\text { Tempo de } \\
\text { escoamento V } \\
\text { funil (s) }\end{array}$ & 2,07 & 1,53 & 3,43 & 2,44 & 2,09 & 2,07 & 1,5 \\
\hline
\end{tabular}
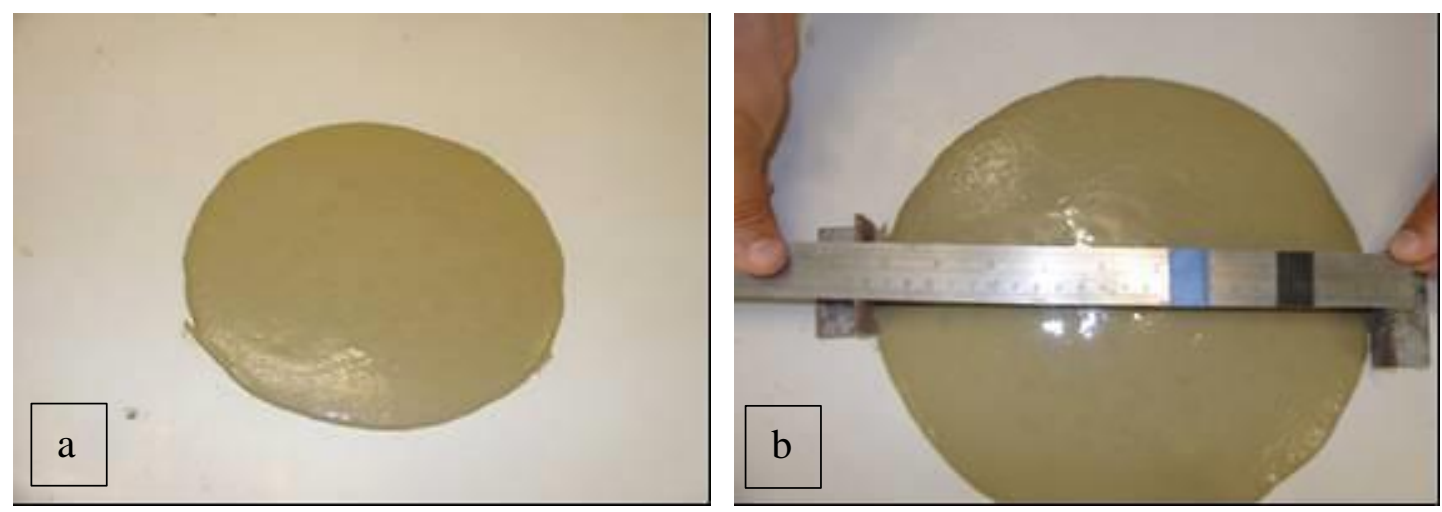

FIGURA 5: Aspectos de superfícies de espalhamento obtidas no estado fresco. 
O Quadro 4 apresenta os principais parâmetros das misturas estudadas, os quais serão úteis para esta análise e dos casos do material endurecido.

Pela observação dos valores apresentados nos Quadros 3 e 4, nota-se que a variação dos diâmetros de espalhamento se apresentaram sensíveis à variação das quantidades da água, do cimento, e do superplastificante na mistura, quando tomados em relação ao solo ou ao cimento, demonstrando ser a água e o superplastificante agentes fluidificantes, e o solo um agente de coesão, coerente com o que é apresentado em BERTÉ e ALCANTARA (2013). As imagens da Figura 5 dão $o$ indicativo de que os ensaios realizados, adotados normalmente para concretos autoadensáveis e argamassas, foram eficazes de modo a caracterizar o comportamento do reológico do material no estado fresco. Os valores relativos ao diâmetro de espalhamento e ao tempo de escoamento em funil se apresentaram de modo geral inversamente proporcionais, o que se mostra coerente com as condições de fluidez do material para este caso. Todavia, convém considerar que os escoamentos livres e confinados se comportam sob regimes diferenciados, podendo haver influências de possíveis flocos na competitividade de acesso ao funil, caso apresentado em BERTÉ e ALCANTARA (2013), ou de choques inter-granulares, conforme a granulometria, de modo que as condições de viscosidade podem contribuir para o melhor comportamento das misturas no escoamento confinado ALCANTARA (2004).

Quadro 5 apresenta os resultados dos ensaios mecânicos no estado endurecido, quando em ensaios de resistência à compressão simples, e em ensaios de flexão, respectivamente, distinguindo-se os valores médios, o desvio padrão e o coeficiente de variação, para as misturas do estudo.

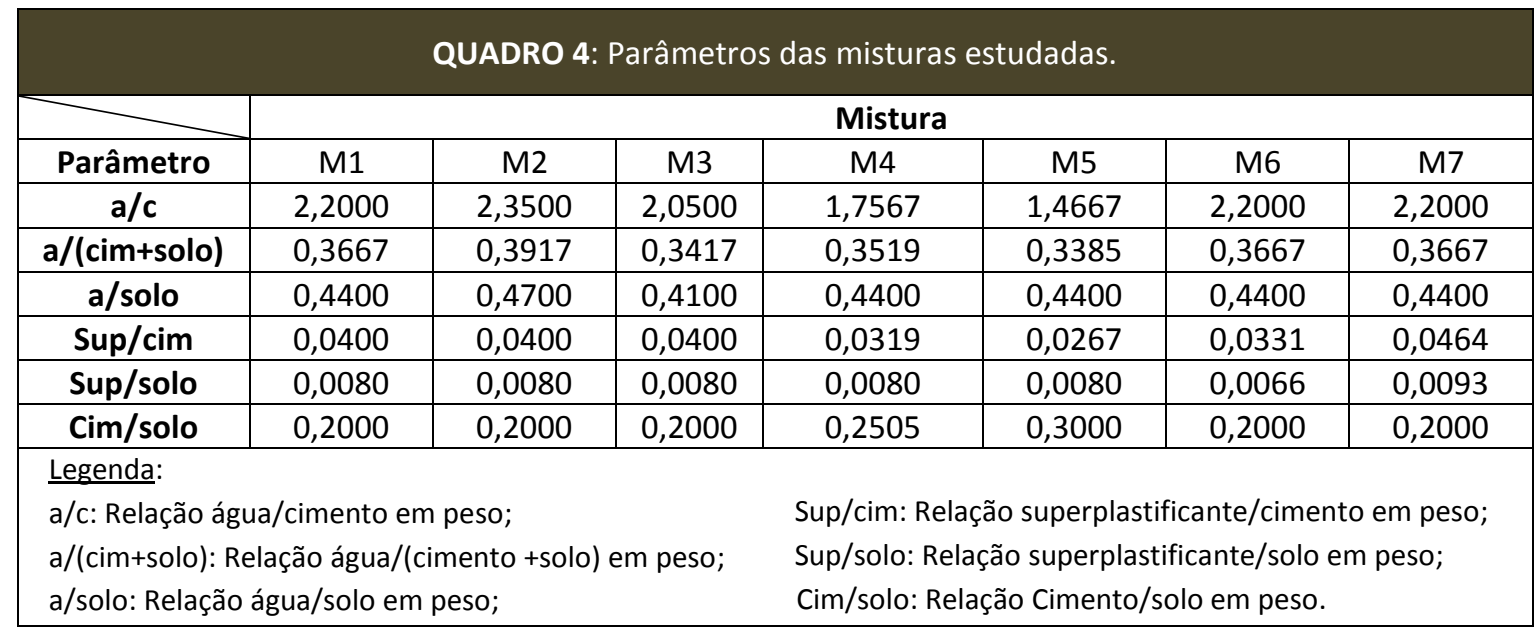

QUADRO 5: Resultados dos ensaios no estado endurecido em ensaios de resistência mecânica.

\begin{tabular}{|c|c|c|c|c|c|c|c|}
\hline \multirow{2}{*}{} & \multicolumn{7}{|c|}{ Resultados dos ensaios no estado endurecido em ensaios de resistência à } \\
compressão simples \\
\cline { 2 - 8 } & \multicolumn{7}{|c|}{ Mistura } \\
\cline { 2 - 8 } & M1-ref. & M2 & M3 & M4 & M5 & M6 & M7 \\
\hline Valor médio (MPa) & 3,170 & 2,704 & 3,735 & 4,856 & 6,492 & 2,926 & 3,172 \\
\hline Desvio padrão & 0,109 & 0,071 & 0,113 & 0,203 & 0,250 & 0,175 & 0,049 \\
\hline $\begin{array}{c}\text { Coeficiente de } \\
\text { variação (\%) }\end{array}$ & 3,439 & 2,618 & 3,022 & 4,178 & 3,843 & 5,984 & 1,529 \\
\hline & \multicolumn{7}{|c|}{ Resultados dos ensaios no estado endurecido em ensaios de flexão } \\
\cline { 2 - 9 } & M1-ref. & M2 & M3 & M4 & M5 & M6 & M7 \\
\hline Valor médio (MPa) & 2,071 & 1,239 & 1,962 & 2,107 & 3,181 & 1,530 & 1,776 \\
\hline Desvio padrão & 0,054 & 0,101 & 0,037 & 0,139 & 0,180 & 0,004 & 0,047 \\
\hline $\begin{array}{c}\text { Coeficiente de } \\
\text { variação (\%) }\end{array}$ & 2,62 & 8,14 & 1,89 & 6,61 & 5,66 & 0,28 & 2,63 \\
\hline
\end{tabular}


Nota-se pelas informações do Quadro 5 que os valores de resistência à flexão se apresentam bastante elevados com relação aos valores de resistência à compressão simples, ao se comparar com os casos de concretos, contudo, a isto se pode atribuir, possivelmente, o nível de rigidez do material em face do patamar alcançado de resistência mecânica quando comparados aos casos dos concretos. A Figura 6 ilustra os valores da resistência mecânica à compressão simples em função dos valores da relação água/cimento, lançando-se no gráfico cada conjunto de misturas. Da mesma maneira, a Figura 7 ilustra os valores da resistência à flexão em função dos valores da relação água/cimento.

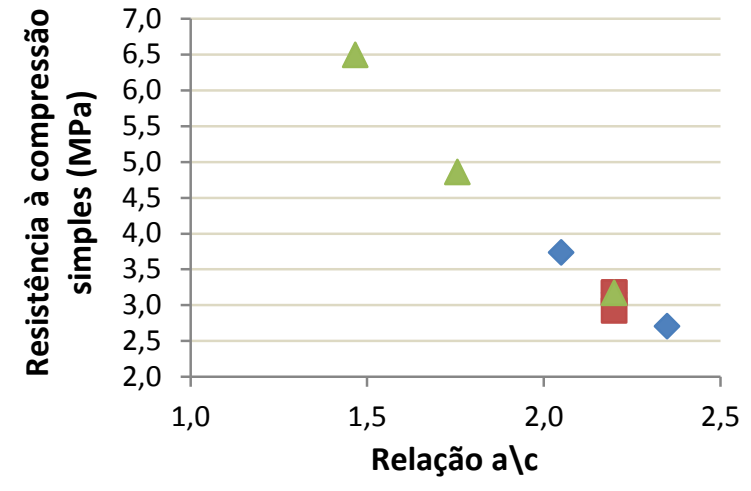

misturas 1,2 e $3 \square$ Misturas 1,6 e $7 \triangle$ Misturas 1,4 e 5

FIGURA 6: Variação da Resistência à compressão simples em função da relação água/cimento, discriminando-se as três séries de misturas.

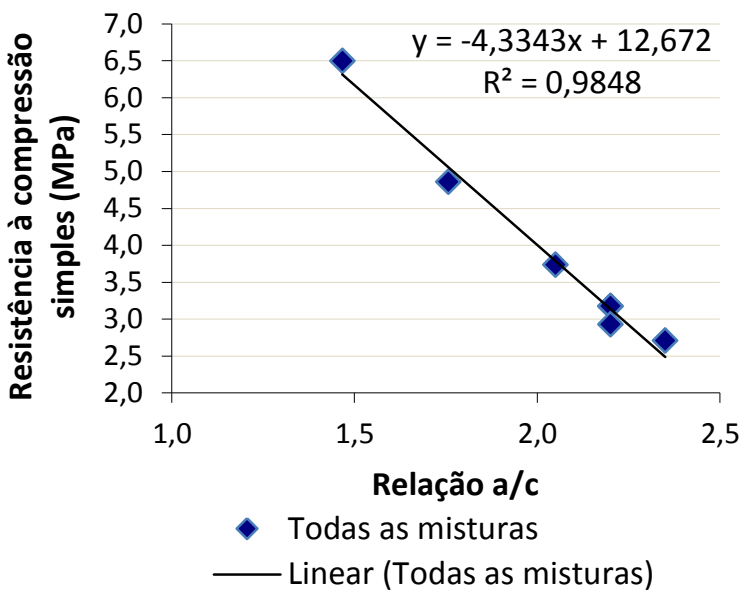

FIGURA 8: Variação da Resistência à compressão simples em função da relação água/cimento, sem discriminação das séries de misturas.
Pode-se observar pelas Figuras 6 e 7 que tanto a variação dos valores da resistência mecânica à compressão simples como os da resistência mecânica à flexão variam de modo inversamente proporcional ao valor da variação da relação água/cimento, de maneira análoga aos casos dos concretos e argamassas. De modo a corroborar o comportamento, as Figuras 8 e 9 procuram ilustrar as possíveis correlações que podem existir entre os valores de resistência à compressão simples e de resistência à flexão com os valores da relação água/cimento, com os respectivos coeficientes de correlação, demonstrando que estas variáveis estão fortemente interligadas.

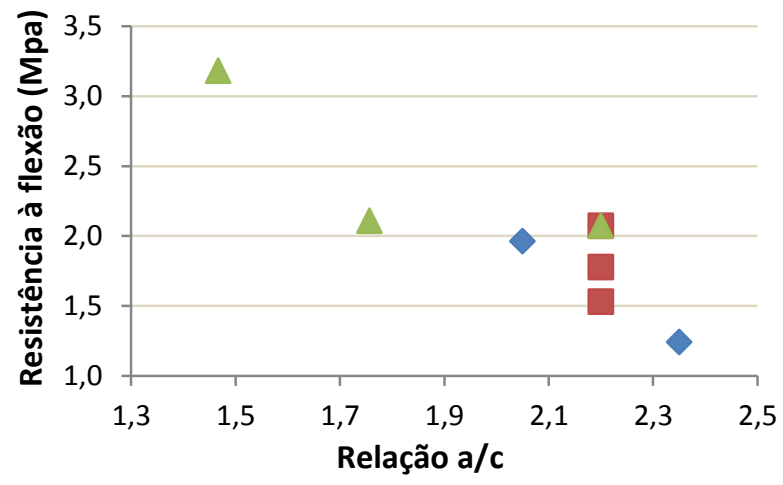

- Misturas 1,2 e $3 \square$ Misturas 1,6 e $7 \triangle$ Misturas 1,4 e 5

FIGURA 7: Variação da Resistência à flexão em função da relação água/cimento discriminando-se as três séries de misturas.

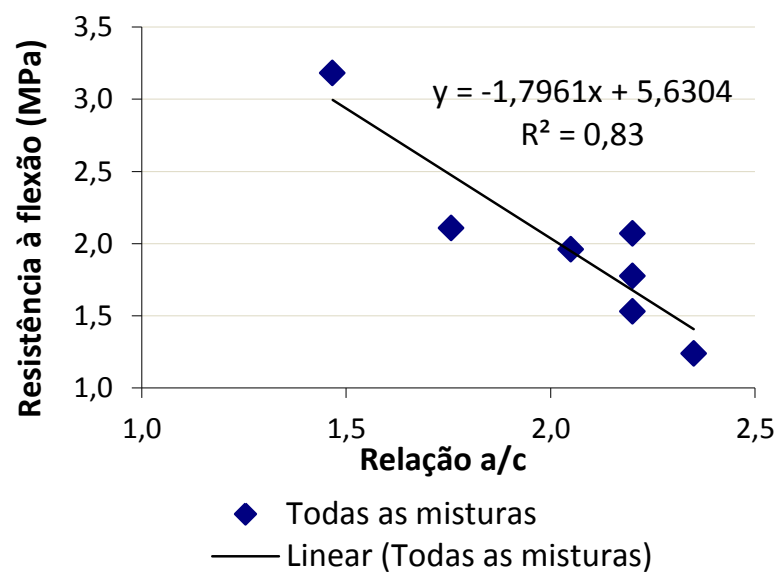

FIGURA 9: Variação da Resistência à flexão em função da relação água/cimento, sem discriminação das séries de misturas. 
A Figura 10, por sua vez, procura ilustrar a variação dos valores da resistência à compressão simples com relação aos da resistência à flexão, identificando o respectivo valor de correlação entre estas variáveis.

Percebe-se que ao aumento do valor da resistência à compressão simples existe concomitantemente o aumento do valor da resistência à flexão, indicando haver cimentação interna do material, e com um comportamento próximo ao linear. A partir disto pode se inferir que o valor da relação "resistência à flexão/resistência à compressão simples", tende a se situar próximo de um determinado valor de referência. Neste sentido, o Quadro 6 apresenta os valores da relação "resistência à flexão/resistência à compressão simples", considerando os diversos adotados casos de mistura.

Conforme o Quadro 6, o valor médio desta relação pode ser dado por 0,530, e sujeito á variação de 0,072 , com coeficiente de variação dado por 0,136. A Figura 11 ilustra a variação do valor da relação "resistência à flexão/resistência à compressão simples". Sugere que, embora haja uma leve tendência ao enrijecimento pela diminuição da relação na curva de tendência, não existe correlação forte entre os valores da relação em função do valor da resistência mecânica, conferindo que, para este material, independentemente do valor da resistência mecânica, o valor da relação deverá se apresentar próximo de um valor invariável.

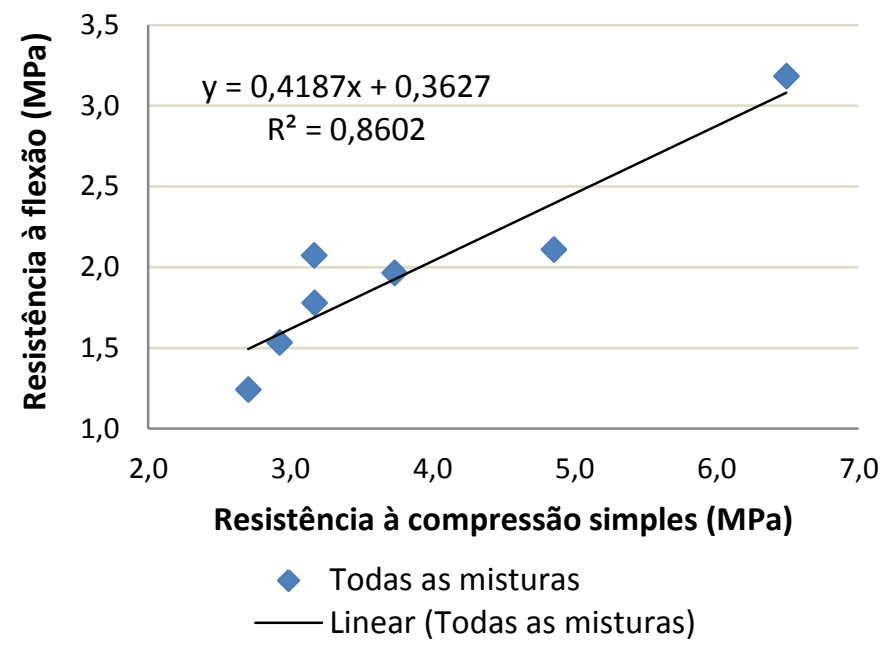

FIGURA 10: Variação do valor da resistência à flexão em função do valor da resistência à compressão simples.

QUADRO 6: Valores da relação "resistência à flexão/resistência à compressão simples", para os diversos valores de resistência mecânica.

\begin{tabular}{|c|c|c|c|c|c|c|c|c|c|}
\hline & \multicolumn{9}{|c|}{ Valores de resistência e relações } \\
\hline & \multicolumn{9}{|c|}{ Mistura } \\
\hline & M1 & $\mathrm{M} 2$ & M3 & M4 & M5 & M6 & M7 & --- & --- \\
\hline $\begin{array}{l}\text { Resistência à } \\
\text { flexão (MPa) }\end{array}$ & 1,239 & 1,53 & 2,071 & 1,776 & 1,962 & 2,107 & 3,181 & --- & --- \\
\hline $\begin{array}{l}\text { Resistência à } \\
\text { compressão } \\
\text { simples (MPa) }\end{array}$ & 2,704 & 2,926 & 3,17 & 3,172 & 3,735 & 4,856 & 6,492 & Média & $\begin{array}{l}\text { Desvio } \\
\text { Padrão }\end{array}$ \\
\hline $\begin{array}{l}\text { Valor da } \\
\text { relação }\end{array}$ & 0,458 & 0,523 & 0,653 & 0,556 & 0,525 & 0,434 & 0,56 & 0,530 & 0,072 \\
\hline
\end{tabular}




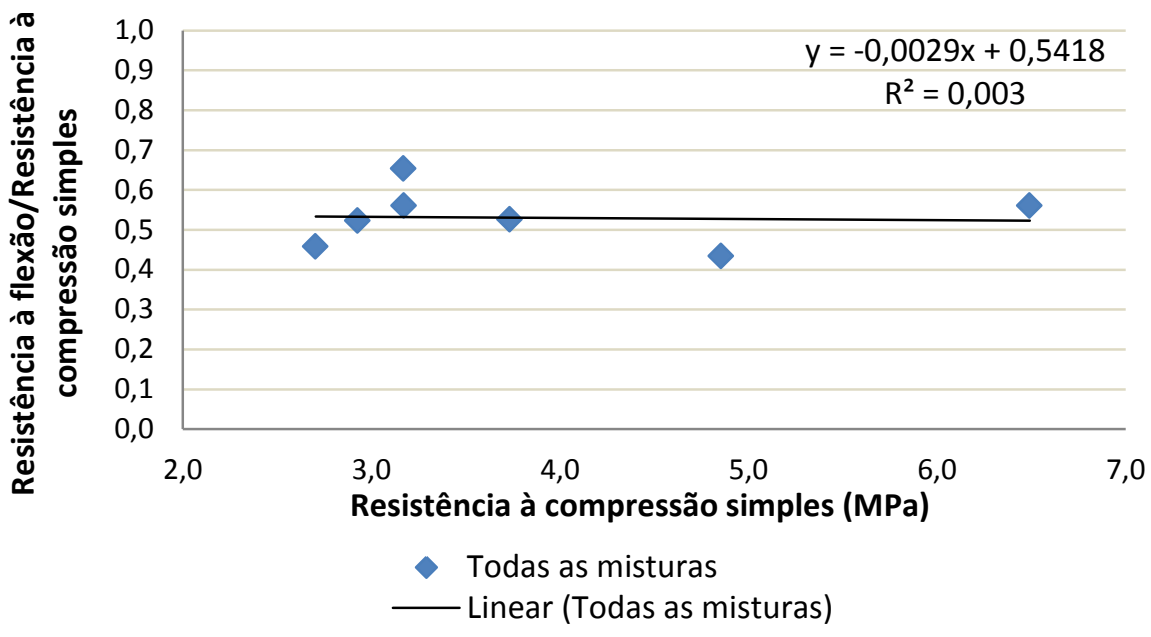

FIGURA 11: Variação do valor da relação "resistência à flexão/resistência à compressão simples" em função do valor da resistência à compressão simples.

O Quadro 7 apresenta os valores das massas específicas aparentes alcançadas para as misturas.

Buscando associar os valores das massas específicas aparentes alcançadas e os valores da resistência á compressão simples, a Figura 12 procura ilustrar a configuração encontrada para os casos dos três tipos de misturas, associando os valores da resistência mecânica aos da massa específica alcançada, e a Figura 13, por sua vez, procura ilustrar a variação do valor da resistência à compressão com o valor da massa específica alcançada, de modo genérico, com o valor da respectiva correlação.

QUADRO 7: Massas específicas aparentes alcançadas pelas misturas no adensamento

\begin{tabular}{|c|c|c|c|c|c|c|c|}
\hline & \multicolumn{7}{|c|}{ Mistura } \\
\cline { 2 - 8 } & M1-ref. & M2 & M3 & M4 & M5 & M6 & M7 \\
\hline $\begin{array}{c}\text { Valor médio } \\
\text { (g/cm } \mathbf{3}\end{array}$ & 1,934 & 1,798 & 1,954 & 2,015 & 1,989 & 1,816 & 1,935 \\
\hline Desvio padrão & 0,10 & 0,05 & 0,10 & 0,041 & 0,038 & 0,127 & 0,035 \\
\hline $\begin{array}{c}\text { Coeficiente de } \\
\text { variação (\%) }\end{array}$ & 4,91 & 2,77 & 4,97 & 2,02 & 1,90 & 6,97 & 1,81 \\
\hline
\end{tabular}

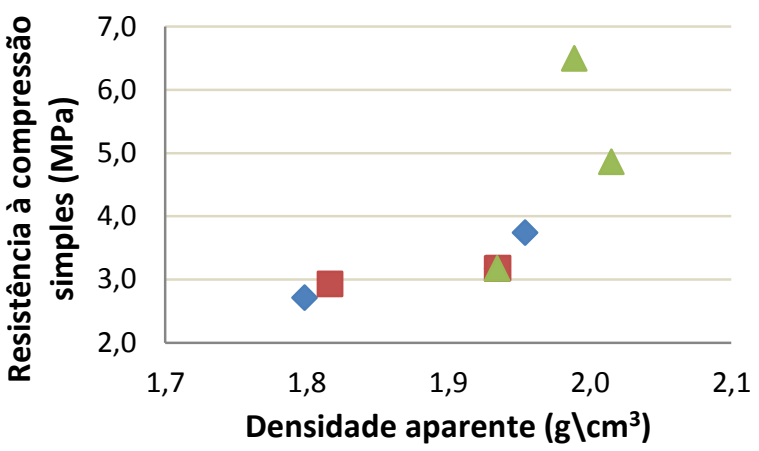

- Misturas 1,2 e 3 Misturas 1, 6 e $7 \triangle$ Misturas 1,4 e 5

FIGURA 12: Variação da Resistência à compressão simples em função do valor da massa específica aparente, discriminando-se as três séries de misturas.

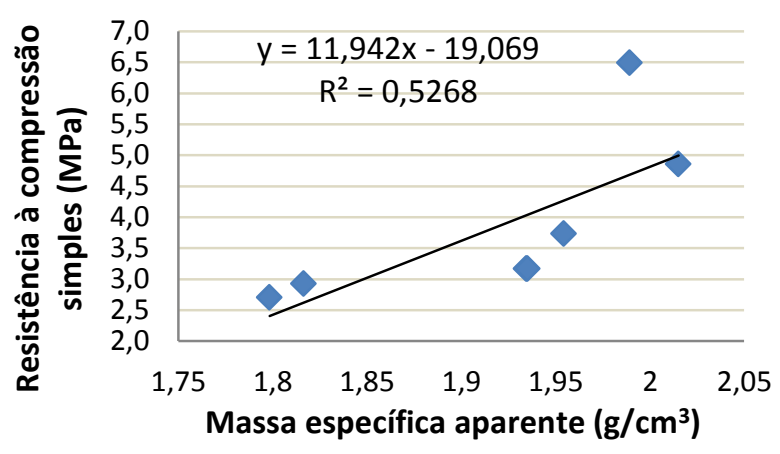

- Todas as misturas _Linear (Todas as misturas)

FIGURA 13: Variação da Resistência à compressão simples em função do valor da massa específica aparente, não discriminando as três séries de misturas. 
Observa-se pelas Figuras 12 e 13 que existe tendência mediana de correlação entre o crescimento do valor da resistência mecânica e o da massa específica aparente. Contudo, observa-se alguma dispersão de resultados, possivelmente pelo fato de que a massa específica aparente da mistura 5 se apresente um pouco estimada com relação às demais. Uma apreciação sem a presença desta é apresentada na Figura 14, a seguir, onde, para esta nova situação, a correlação encontradase apresenta próximo ao valor de uma correlação forte.

Os valores da massa específica aparente tendem a guardar relação com os valores da resistência mecânica, contudo aparentemente o valor da resistência mecânica será influenciado preferencialmente pelo valor da relação água/cimento. A seguir, o quadro 8 apresenta os valores dos ensaios de porosidade realizados para as misturas.

Com base nos valores dos Quadros 7 e 8, a Figura 15 apresenta as possíveis correlações entre os valores da porosidade e os da massa específica aparente, e, a Figura 16 apresenta possíveis correlações entre os valores da porosidade os da resistência mecãnica à compressão simples.

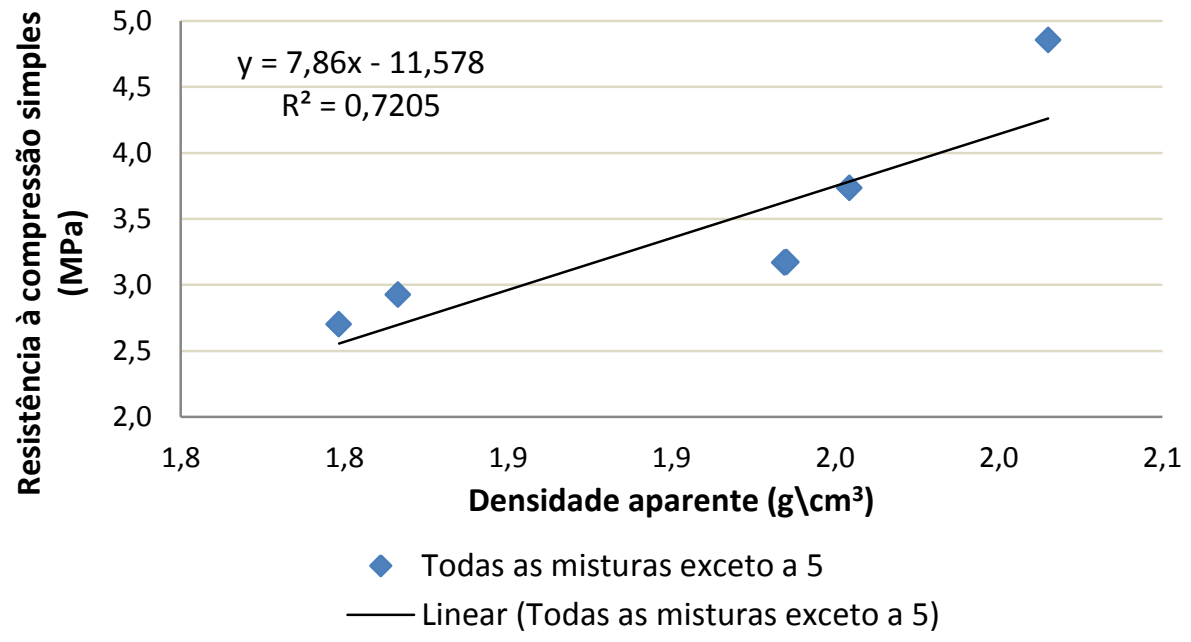

FIGURA 14: Variação da Resistência à compressão simples em função do valor da densidade aparente, sem a mistura 5.

QUADRO 8: Valores alcançados nos ensaios de porosidade para os casos das misturas 1 a 7.

\begin{tabular}{|c|c|c|c|}
\hline Mistura & $\begin{array}{c}\text { Valor Médio } \\
\text { (\%) }\end{array}$ & $\begin{array}{c}\text { Desvio } \\
\text { Padrão }\end{array}$ & $\begin{array}{c}\text { Coeficiente de } \\
\text { Variação } \\
\text { (\%) }\end{array}$ \\
\hline M1 & 47,40 & 0,85 & 1,8 \\
\hline M2 & 48,41 & 1,20 & 2,5 \\
\hline M3 & 41,55 & 0,37 & 0,9 \\
\hline M4 & 41,71 & 0,62 & 1,5 \\
\hline M5 & 43,16 & 2,84 & 6,6 \\
\hline M7 & 44,5 & 0,54 & 1,2 \\
\hline
\end{tabular}




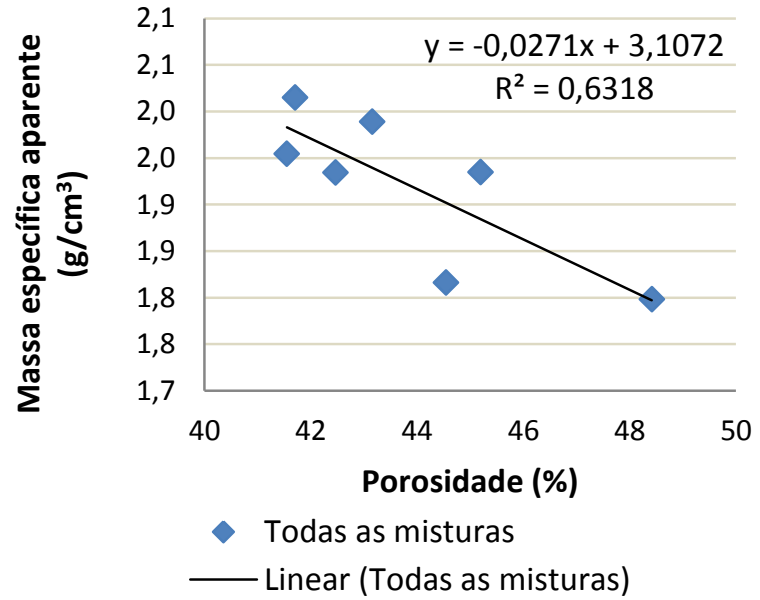

FIGURA 15: Possíveis correlações entre os valores de porosidade e os valores de massa específica aparente.

Os resultados apresentados nas Figuras 15 e 16 indicam haver relação bastante mediana entre os índices de porosidade e os valores da massa específica aparente, e baixa relação com os valores da resistência mecânica. Os valores da resistencia à compressão simples nos diversos casos de mistura aparentemente são resultantes da estrutura formada pela pasta hidratada de cimento Portland, assim como, a massa específica alcançada pelas misturas auto-adensadas pode ter sofrido efeitos de natureza físico-química, de floculação ou de dispersão, com base na interferência da acalinidade no sistema coloidal. Neste sentido, o

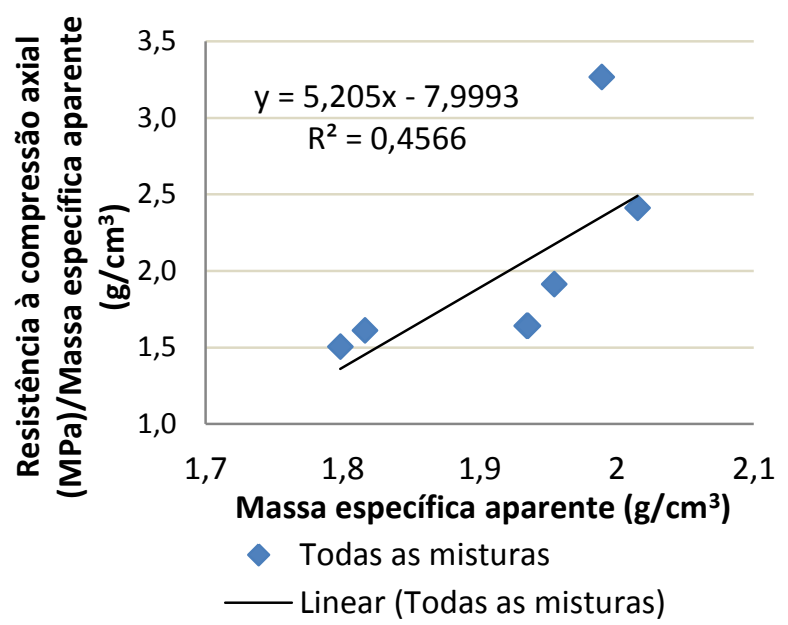

FIGURA 17: Resistência mecânica axial/massa específica aparente e a massa específica aparente.

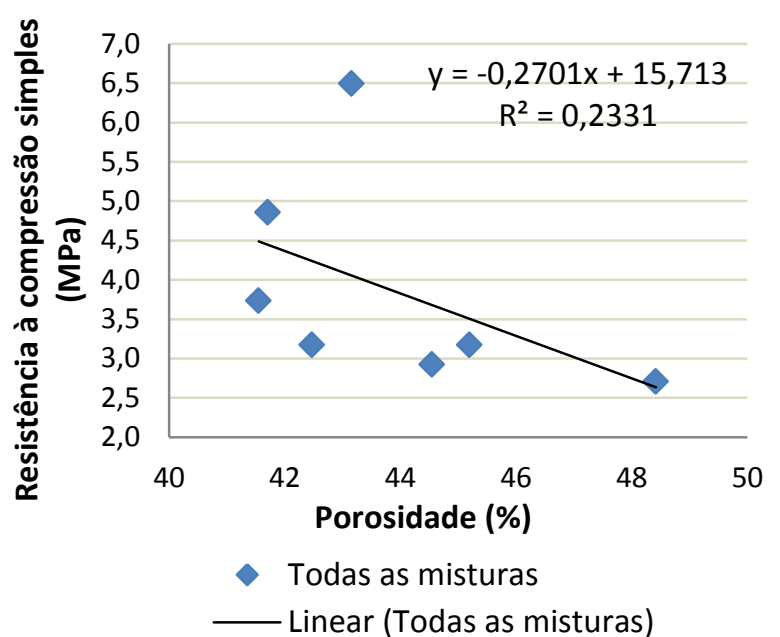

FIGURA 16: Possíveis correlações entre os valores de porosidade e os valores de resistência mecânica.

material solo-cimento auto adensável tende a fugir do escopo do solo-cimento compactado, onde, dentro de certos limites, o valor da massa específica alcançada deixa de ser determinante para o nível alcançado de resistência mecânica. Se considerar o "Fator de eficiência" como sendo a relação "Resistência mecânica axial/massa específica aparente", a Figura 17 procura ilustrar a variação desta relação com os valores da massa específica aparente, e, da mesma forma, a Figura 18 procura os correlacionar esta variável com os valores da resistência mecânica axial. Para tanto são consideradas todos os casos de mistura.

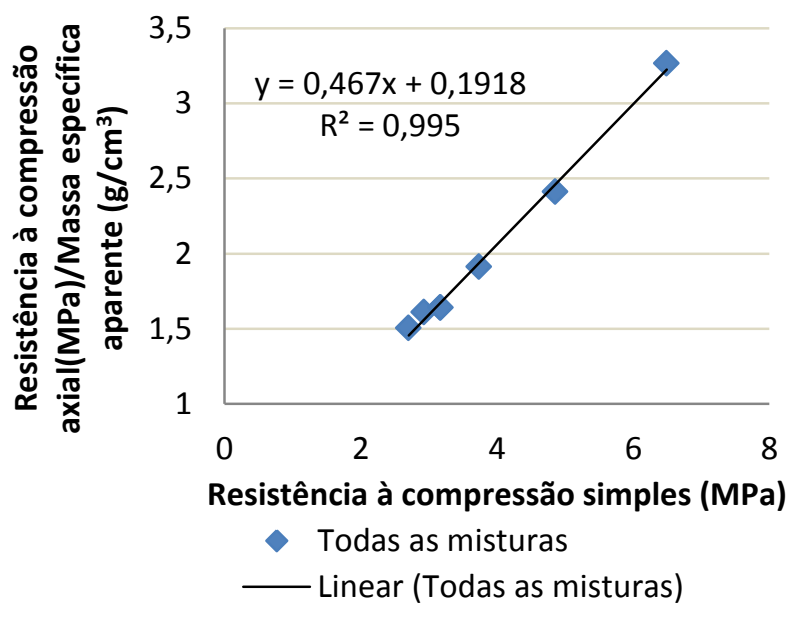

FIGURA 18: Resistência mecânica axial/massa específica aparente e a resistência à compressão axial. 
Observa-se que o valor do Fator de eficiência se apresenta correlacionado preferencialmente com o valor da resistência à compressão axial do que com o valor da massa específica alcançada, fornecendo um indicativo de que o ganho de resistência mecânica é favorecido com o nível de cimentação interna do material do que com o nível de compacidade. Em confirmação à possível influência da cimentação interna preponderante neste tipo de estabilização, decorrente das reações de hidratação do cimento, a Figura 19 apresenta variação da relação "Resistência mecânica axial/massa específica aparente" com a variação dos valores da relação água/cimento, de onde se depara que, com o aumento do valor desta variável, a relação ou fator de eficiência tende a diminuir, indicando que o papel da hidratação do cimento se torna menos relevante.

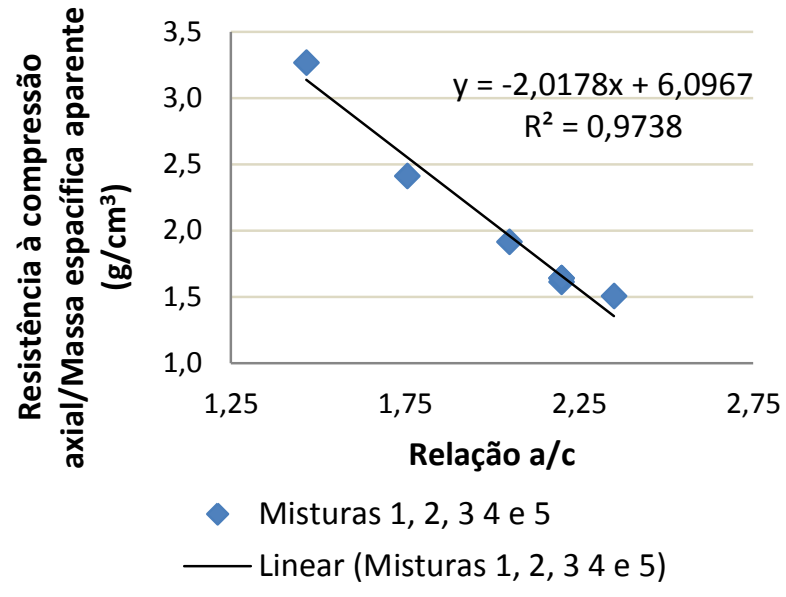

FIGURA 19: Resistência mecânica axial/massa específica aparente e a relação água/cimento.

\section{CONCLUSÃO}

De acordo com os resultados apresentados, conclui-se que:

- as misturas de solo-cimento auto-adensável podem ter como parâmetro de dosagem o valor da relação água/cimento para definir o comportamento mecânico, tanto quando considerados os casos da resistência à compressão simples como nos casos da resistência à flexão.

- Os valores da massa específica aparente tendem a guardar relação com os valores da resistência mecânica, contudo, aparentemente, os valores da resistência mecânica se apresentaram influenciados preferencialmente pelo valor da relação água/cimento.

- O solo-cimento autoadensável demonstrou ter como fator de ganho de resistência mecânica o processo de hidratação do cimento, de modo que 0 Fator de eficiência pode ser preferencialmente influenciado pela relação água/cimento.

- As misturas de solo, cimento, água e aditivosno estado fresco se mostraram eficazes quando avaliadas por meio de ensaios adotados normalmente para o estudo de concretos auto-adensáveis e argamassas. Os ensaios se mostraram eficazes para avaliar as tendências de comportamento e qualificação no estado fresco, do mesmo modo que para os casos de concretos e argamassas.

Diante dos níveis alcançados para o valor da resistência mecânica, como sugestões para a contunuidade do estudo, considera-se relevante um estudo sobre a durabilidade do material, envolvendo condições diferenciadas de exposição, e sob períodos mais prologados, de modo a melhor compreender a preservação da capacidade portante para esse material. Ainda, considerando também que 0 material seja enquadrado o comportamento próximo ao dos concretos e das argamassas, pode se considerar importante de um estudo a partir da incorporação de fibras a este, de modo a poder explorar as possibilidades de atribuir ductilidade ao material,e que possam ser explorados na fabricação de elementos construtivos.

\section{AGRADECIMENTOS}

Agradecemos à UNESP, programa de melhoria da pós-graduação, pelo auxílio financeiro para a realização deste estudo, à FEUPUNIVERSIDADE DO PORTO, e ao LABEST, pelo apoio recebido para a realização da pesquisa, e a Revista Eletrônica de Engenharia Civil, REEC-UFG, pela oportunidade de divulgação deste trabalho. 


\section{REFERÊNCIAS BIBLIOGRÁFICAS}

ALCÂNTARA, M. A. M. Bétons auto-plaçants et fibrages hybrides: composition, rhéologie et comportement mécanique. 2004. Tese (Doutorado em Engenharia Civil) - Institut National des Sciences Appliquées - INSA, Toulouse, 2004. 192p.

BERTE, S. D. D; ALCANTARA, M. A. M. Estudo do comportamento do solo-cimento auto-adensável. REEC - Revista Eletrônica de Engenharia Civil - ISSN 2179-0612, v. 7, n. 2, p. 16-31, 2013.

CONSOLI, N. C.; FOPPA, D.; FESTUGATO, L; HEINECK, K. S. Key parameters for Strength Control or Artificially Cemented Soils. Journal of Geotechnical and Geoenvironmental Enginnering, New York, v. 133, n. 2, p.197-205, 2007.

FONSECA, A. V; CRUZ, R. C; CONSOLI, N. C. Strength properties of a sandy soil-cement admixtures. Journal Geotechnical \& Geological Engineering, Oklahoma, v. 27, n. 6, p. 681-686. 2009.

HORPBILSUK, S.; MIURA N.; NAGARAJ, T. S. Assessment of strength development in cement-admixed high water content clays with Abram's law as a basis. Geotechnique Journal, Bangalore, v. 53, n. 4, p. 439-444, 2003.

INSTITUTO PORTUGUÊS DE QUALIDADE - IPQ. Método de ensaios de cimentos, parte 1: Determinação das resistências mecânicas. 37p. 1996.

NUNES, S. C. B. Betão Auto-Compactável: Tecnologia e Propriedades. Dissertação de Mestrado. Faculdade de Engenharia da Universidade do Porto, Porto, Setembro, 2001. 198p.

SEGANTINI, A. A. S; ALCANTARA, M. A. M. Solo-cimento e solo-cal. In: INSTITUTO BRASILEIRO DE CONCRETO IBRACON (Org.). Materiais de construção civil e princípios básicos de ciência e engenharia de materiais. 2. ed. São Paulo: IBRACON, 2010. v. 2, p. 863-891. 